\title{
Pediatric Admissions by Family Physicians and Pediatricians in a Semirural Environment: Implications for Residency Training
}

\author{
Jobn G. Bertolino, MD, MSPH, and Thomas P. Gessner, MD
}

Background: The 3-year family practice residency curriculum includes longitudinal care of children in the family health center and a 4-month experience dedicated to the care of children. This study was designed to compare the diseases of hospitalized children cared for by family physicians and pediatricians and to examine the use of pediatricians as consultants by family physicians.

Methods: The study included all patients younger than 18 years who were discharged by a family physician or a pediatrician from this semirural hospital during a 3-year period. The primary discharge diagnosis, physician, consultations, and transfer status were recorded.

Results: Family physicians cared for 37 percent of the $\mathbf{4 1 6 9}$ pediatric patients discharged during the study. Infectious diseases and their complications were the most common conditions for patients who were discharged beyond the newborn period. The 15 most frequent discharge diagnoses were identical for family physicians and pediatricians, accounting for about 86 percent of all discharge diagnoses. Pediatricians, however, cared for 86 percent of the newborns with major complications and were responsible for 80 percent of the infants and children who were transferred. The overall inpatient consultation rate of pediatricians by family physicians was 8 percent, whereas the consultation rate for nonneonatal-related discharges was 20 percent.

Conclusion: In this semirural environment, family physicians and pediatricians care for a very similar mix of hospitalized pediatric patients. Pediatricians, however, care for a greater proportion of newborns with major complications. (J Am Board Fam Pract 1999;12:128-32.)

Pediatric training is an essential part of family practice residency education, with current Residency Review Committee for Family Practice guidelines requiring 4 months of training dedicated to the care of children. ${ }^{1}$ These 4 months are included in the 3-year longitudinal experience in the family health center, which also includes the care of children. Data regarding the principal reasons for a patient visit in the ambulatory sector ${ }^{2}$ show that respiratory symptoms, infections, and well-patient care appear to be common reasons for patient visits to the physician. There is limited information, however, regarding the types of hospitalized pediatric patients cared for by family physicians. A recent report comparing the inpatient work of family physicians and pediatricians in rural areas described a similar case mix between these two groups of physicians. ${ }^{3}$ One exception

Submitted, revised, 30 September 1998

From the Family Practice Residency (JGB) and the Latrobe Area Hospital (TPG), Latrobe, Pa. Address reprint requests to John G. Bertolino, MD, MSPH, Family Practice Residency Program, Latrobe Area Hospital, 121 West Second Ave, Latrobe, PA 15650. was that pediatricians were more likely to care for low-birth-weight infants.

In addition to the limited amount of information comparing the inpatient case mixes of family physicians and pediatricians, we found no studies examining the use of pediatricians as inpatient consultants by family physicians. The need for primary care providers, the decline in the volume of inpatient pediatric care ${ }^{4}$ and the ever-present threatened funding for graduate medical education should force our specialty to examine ways in which family physicians can be most efficiently trained to care for children. Comparing and contrasting discharge diagnoses and consultation patterns of family physicians and pediatricians will provide insight regarding the diseases that family physicians should encounter in training to be prepared for practice. Accordingly, this information could be used to adjust curriculum, and finally it could be used to justify the simultaneous use of training resources by family practice and pediatric educators.

This study was undertaken to compare the case mix of inpatient care rendered by family physi- 
cians and pediatricians and to examine the consulting and transfer trends of these provider groups in a semirural environment.

\section{Methods}

All patients younger than 18 years of age discharged from Latrobe Area Hospital from January 1995 until December 1997 were included in the study. The Sachs Group Market Planner by the Sachs Group (Evanston, Ill) was used to generate a list of discharge diagnoses, including the number of patients with each diagnosis, for all family physicians and pediatricians during the 3-year period. The information program Hospital Patient Management System, by HBO and Company (Atlanta), was used to supply a list of patient transfers to another acute care facility and consultations done by pediatricians during the same time. Only patients discharged from a family practice or general pediatric service were included in the study. Pediatric consultations requested only by family physicians were included in the analysis. The discharge diagnosis was considered to be that diagnosis listed first by the attending physician. Comorbid diagnoses were not analyzed.

Each patient discharge was counted as a separate case regardless of the number or nature of the patient's previous discharges. Newborns with any discharge diagnosis, including the diagnosis of normal newborn, were analyzed separately. For purposes of this study, the term newborns applies to all patients 7 days of age or younger. Infants and children include those patients older than 7 days and younger than 18 years.

\section{Results}

At the time of the study the Latrobe Area Hospital was a 250 -bed facility with a level II nursery. The hospital, situated within the 15,000 person semirural community of Latrobe, $\mathrm{Pa}$, serves a population of 120,000 . Approximately 22 percent of the population was younger than 17 years, and 98 percent of all patients making office visits was white. Two pediatric offices and 13 family practice offices staffed by 9 pediatricians and 31 family physicians cared for the children, infants, and newborns in the area during the study. About one half of the family physicians were employed by the hospital and practiced in five separate offices throughout the service area. Three of these offices were part of the 18-resi- dent Family Practice Residency Program, which was begun in 1974. Sixty percent of the family physicians on staff at the hospital were graduates of the residency program.

All family physicians had level I pediatric and nursery privileges. Physicians at this level are allowed to care for all common pediatric problems in which the diagnosis is readily apparent, the patient is expected to do well with standard treatment, and there is no obvious potential for disability or death. Delivery room consultation requests by obstetricians for assistance in caring for potential or existing problems of newborns were made exclusively to pediatricians. Family practice residents attended all of the consultations with the pediatricians. In addition, all premature infants were routinely assigned to the pediatric service. The family practice residents regularly rotated on the inpatient pediatric services, spent time in the pediatric offices, and while on call were responsible for all inpatients on and admissions to the pediatric services. During the 3-year period, approximately 50 percent of the patients were insured through managed care contracts.

During the study period there were 4169 discharges of patients younger than 18 years. The 31 family physicians cared for 37 percent of these patients, and the remainder were cared for by the 9 pediatricians. Newborns accounted for 2640 of these discharges, and family physicians cared for 35 percent of these patients. Family physicians cared for 40 percent of the infants and children, patients who were older than 7 days and younger than 18 years of age.

The 15 most common discharge diagnoses for infants and children, and the frequencies with which they occurred with family physicians and pediatricians, are listed in Table 1 . Infectious diseases and their complications were the predominant reasons for pediatric hospitalizations. Overall there are few major differences in the discharge diagnoses of patients cared for by family physicians and pediatricians. Family physicians, however, appeared to care for a disproportionally higher percentage of patients with simple pneumonia and pleurisy, seizure and headache, diabetes, and poisoning and toxic reactions. The 15 most common discharge diagnoses for infants and children accounted for 86 percent of all patients' discharge diagnoses during the 3-year period. Furthermore, the 5 most common diagnoses ac- 
Table 1. Fifteen Most Common Discharge Diagnoses in Infants and Children and Percentage of Patients With Each Diagnosis by Specialty.

\begin{tabular}{|c|c|c|}
\hline Diagnosis & $\begin{array}{c}\text { Family } \\
\text { Physicians } \\
(\mathrm{n}=31)\end{array}$ & $\begin{array}{l}\text { Pediatricians } \\
\quad(\mathrm{n}=9)\end{array}$ \\
\hline Bronchitis and asthma & 17 & 25 \\
\hline Dehydration & 15 & 14 \\
\hline Gastroenteritis & 13 & 15 \\
\hline Simple pneumonia and pleurisy & 9 & 7 \\
\hline $\begin{array}{l}\text { Viral illness or fever of unknown } \\
\text { origin }\end{array}$ & 7 & 6 \\
\hline $\begin{array}{l}\text { Otitis media and upper respiratory } \\
\text { tract infection }\end{array}$ & 5 & 4 \\
\hline Kidney and urinary tract infection & 4 & 5 \\
\hline Seizure and headache & 5 & 2 \\
\hline Cellulitis & 2 & 2 \\
\hline Diabetes & 3 & 1 \\
\hline Poisoning and toxic reaction of drugs & Igs 3 & 1 \\
\hline Laryngotracheitis & 1 & 1 \\
\hline Other ear, nose, and throat diagnoses & ses 0 & 2 \\
\hline Viral meningitis & 1 & 1 \\
\hline Respiratory signs and symptoms & 1 & 1 \\
\hline $\begin{array}{l}\text { Percent of total patients with a } \\
\text { top } 15 \text { diagnosis }\end{array}$ & 86 & 87 \\
\hline $\begin{array}{l}\text { Total number of patients, } \\
\text { all diagnoses }\end{array}$ & 619 & 910 \\
\hline
\end{tabular}

Note: For this study infants and children are those patients older than 7 days and younger than 18 years.

counted for 65 percent of all infants' and children's discharge diagnoses.

Family physicians cared for 38 percent of the normal newborns. Newborns with any problems, especially those who had serious problems, were premature, or required transfer, were much more likely to be cared for by a pediatrician than by a family physician (Table 2). Family physicians cared for only 14 percent of the patients in these last three groups and only 3 percent of the premature newborns with serious problems and those newborns requiring transfer.

There were 101 transfers of children, infants, and newborns to another acute care facility during the 3-year period. Eighty percent of these transfers were from the pediatric services, and 12 percent were from the family physician services. Sixty percent of all transfers were for newborn problems; these transfers were almost exclusively from the pediatric services.

One quarter of the infants and children who were transferred had a respiratory indication for their transfer. Approximately one half of these transfers were from the pediatric services.

Family physicians requested 130 pediatric consultations during the 3 -year period. Overall the rate at which family physicians consulted pediatricians for all pediatric patients discharged from the family practice services was 8 percent. There were 121 consultations for discharge diagnoses relating to infants and children, resulting in a discharge consultation rate of 20 percent. The consultation rate for all newborns was 1 percent; however, the consultation rate for newborns with any serious problems was 64 percent.

For the 15 most common discharge diagnoses, family physicians sought pediatric consultation for all conditions except otitis media and other ear, nose, and throat diagnoses (Table 3). The highest rates of consultation for the 15 most common diagnoses were for viral meningitis, poisoning and toxic drug reactions, seizure and headache, respiratory signs and symptoms, viral illness or fever of unknown origin, and diabetes. Seven diagnostic categories (seizure and headache, simple pneumonia and pleurisy, bronchitis and asthma, gastroenteritis, dehydration, neonatal problems, and viral illness or fever of unknown origin) accounted for two thirds of all pediatric consultations.

\section{Comment}

This study, which was conducted in a semirural environment where all pediatricians are active in family practice residency education and where one half all family physicians on staff are graduates of the same residency program, shows that there are remarkable similarities between the types of discharge diagnoses rendered by pediatricians and family physicians. Indeed, 86 percent of their patients share the same 15 diagnoses. The 9 pediatricians cared for 60 percent and the 31 family physicians cared for 40 percent of the infants and children discharged from the two services.

There are some differences between the patients discharged by pediatricians and family physicians. Pediatricians cared for proportionally more infants and children with asthma, laryngotracheitis, and other ear, nose, and throat diagnoses. The major difference in the care provided by pediatricians and family physicians in this setting appears to be in the area of complicated newborns. Pediatricians cared for 86 percent of the newborns who had serious problems and 97 percent of the 
Table 2. Percentage of Newborns Cared for by Family Physicians and Pediatricians, by Diagnosis.

\begin{tabular}{lccc}
\hline Discharge Diagnosis & $\begin{array}{c}\text { Family } \\
\text { Physicians } \\
\%\end{array}$ & $\begin{array}{c}\text { Pediatricians } \\
\%\end{array}$ & $\begin{array}{c}\text { Total Newborns } \\
\text { With Diagnosis } \\
\text { No. }\end{array}$ \\
\hline Normal newborns & 38 & 62 & 2040 \\
Newborns with minor problems & 29 & 71 & 277 \\
Newborns with major problems & 20 & 80 & 120 \\
Premature & 27 & 73 & 96 \\
Extreme immaturity or premature with major problems & 2 & 98 & 47 \\
Neonate transferred & 3 & 97 & 60 \\
Total number of newborns & 915 & 1725 & 2640 \\
\hline
\end{tabular}

For this study newborns are patients who are 7 days old or younger.

premature newborns with major problems and newborns requiring transfer to a higher level of care. Pediatricians, in general, tended to care for most newborns, infants, and children who required transfer, regardless of the age of the child. This finding suggests that the pediatricians tended to care for patients who were at more risk for complicated, severe, or unusual illnesses.

Family physicians most commonly consulted pediatricians for inpatient care when the situations involved infections, especially of the respiratory system, seizure and headache, and newborns with problems. This latter phenomenon might be because consultation requests by obstetricians for distressed newborns were always made to pediatricians, not family physicians. Family physicians, however, were able to care for 80 percent of their hospitalized infants and children without pediatric consultation.

This information suggests a competency list of pediatric problems that family physician educators should consider when evaluating the inpatient training of their resident physicians. Family physicians and pediatricians had common rates of discharge diagnoses, which suggests there could be considerable sharing of inpatient resources to train family practice and pediatric residents. Those family physicians who elect to practice in areas without pediatric support should be trained to manage problems of newborns, especially those who are premature or who have illnesses severe enough to require transfer to an acute care facility for more definitive care. It is noteworthy that family physicians tended to obtain pediatric consultation for problems associated with diabetes, poisoning and toxic drug reactions, and seizure and headache, all diagnostic categories in which they care for a disproportionately high percentage of infants and children. On average, during 3 years of residency 6 family practice residents would have the opportunity to care for a total of 89 patients with these three disorders. Perhaps family physicians planning to practice in areas where there are no pediatricians should have their education structured to take advantage of educational opportunities in these areas of medicine.

When generalizing these results, it is important to take into consideration the racial composition of the practice, the semirural setting, and the

Table 3. Frequency of Pediatric Consultation by Family Physicians for 15 Most Common Discharge Diagnoses in Infants and Children.

\begin{tabular}{lc}
\hline Diagnosis & $\begin{array}{c}\text { Percent of Family } \\
\text { Practice Patients } \\
\text { With Pediatric } \\
\text { Consultation }\end{array}$ \\
\hline Viral meningitis & 60 \\
Poisoning and toxic reaction of drugs & 50 \\
Seizure and headache & 48 \\
Respiratory signs and symptoms & 40 \\
Viral illness and fever of unknown origin & 35 \\
Diabetes & 33 \\
Bronchitis and asthma & 23 \\
Laryngotracheitis & 20 \\
Kidney and urinary tract infection & 19 \\
Simple pneumonia and pleurisy & 15 \\
Gastroenteritis & 14 \\
Dehydration & 11 \\
Cellulitis & 8 \\
Otitis media and upper respiratory tract infection & 0 \\
Other ear, nose, and throat diagnoses & 0 \\
\hline
\end{tabular}

Note: For this study infants and children are those patients older than 7 days and younger than 18 years. 
homogeneous teaching environment (one half of the family physicians in the study were trained by the pediatricians in the study). Nevertheless, the results of a rural Washington study ${ }^{3}$ are similar to ours and support our findings regarding the casemix similarities and differences between pediatricians and family physicians. In addition, an estimated 37 percent of family physicians practice in communities the same size as ours or smaller, ${ }^{5}$ and 17 percent of pediatricians practice in communities of similar size. ${ }^{6}$ It would seem, therefore, that our findings could be applicable to other practice sites. Combining urban and rural data, while providing greater numbers of patient diagnoses for comparison, might obscure important distinctions that exist between diverse practice environments.

Discharge diagnoses were validated by attending physician signatures, but comorbid conditions were not included in this analysis. Although our general impression was that pediatricians might have cared for more children who were ill, for more children who had comorbid conditions, or for more children who had developmental or other physical disadvantages that would complicate their care, we cannot accurately validate that impression with this study. In addition, other than the neonatal analysis, there was no consideration made for a possible difference in age distribution that might have existed between those children discharged from the two services.

Finally, it is difficult to determine how the study was affected by the involvement of family practice residents at all three levels of training who in many cases were responsible for the decision to admit patients or to obtain pediatric consultation on patients.

In conclusion, a limited number of diagnoses, primarily involving infectious diseases and their complications, were responsible for most pediatric inpatient problems for both family physicians and pediatricians. A list of these diagnoses should be of value to family practice educators when reviewing and structuring the residency curriculum. It could be used to ensure that residents are exposed to a case mix of relatively common conditions, which should be similar to those they would encounter in their practice after graduation. Because of the similarity in discharge diagnoses between family physicians and pediatricians practicing in a semirural community, it is reasonable to assume that their inpatient training could be integrated to take advantage of educational resources. Those family physicians who anticipate practicing in areas where pediatricians are not readily available should consider additional training in the care of newborns with problems.

\section{References}

1. Requirements for residency education in family practice. In: Manual of policies and procedures for graduate medical education review committees. Chicago: Accreditation Council for Graduate Medical Education, 1997.

2. Rakel RE. The family physician. In: Rakel RE, editor. Textbook of family practice. 5 th ed. Philadelphia: WB Saunders, 1995.

3. Melzer SM, Grossman DC, Hart LG, Rosenblatt RA. Hospital services for rural children in Washington State. Pediatrics 1997;99:196-203.

4. Health, United States, 1996-97. Huntsville, Md: Department of Health and Human Services, Public Health Service, Centers for Disease Control and Prevention, National Center for Health Statistics, 1998:209.

5. Practice profile survey. Kansas City, Mo: American Academy of Family Physicians, 1997.

6. Periodic survey of fellows, No. 38. Elk Grove Village, Ill American Academy of Pediatrics, 1998. 